\title{
Too little Indian zeal
}

SIR - To my mind, the basic problem with Indian academics is that their sense of social responsibility is often regrettably poor. Only a very few educated people are ready to produce an amount of work that will justify their salaries. Even in a research institution such as the Tata Institute of Fundamental Research, where the annual input is equivalent to US\$6 million, the annual output is about 270 research publications in the journals, shared by more than 300 top-level scientists. These scientists are potentially as capable as their counterparts in the West, but we become lazy in our home country. The very same people, when abroad, are compelled (possibly by example) to work hard, each producing as many as 5-10 papers a year. I am not saying that quantity is a measure of quality, but I certainly believe that, for the average research worker, quantity does beget quality.

The situation is much worse in Indian universities and other research organizations, which submit thousands of eyewashing project reports to their financiers, in preference to publication in one of the standard journals. Mainly on the basis of these obscure reports, however, the government measures national progress. Notwithstanding the rosiness of any such picture, the country seems to receive a poor return for its heavy investment. People are adequately paid for working, but the moral sense of their official responsibility fails to meet the minimum standard.

Mrs Indira Gandhi made a very brave attempt to improve matters by imposing emergency rule in 1976. All officials in positions of responsibility were forced to keep full office hours and to carry out their duties properly. This obviously irked all the educated parasites, who successfully brought about a ballot-paper revolution against her. So the poor lady has now learned that morality cannot be taught by force. We must rely on an appeal to people's individual consciences for any improvement - and I have written this letter in order to make such an appeal. A country can progress only if every citizen is willing to carry out his or her job responsibilities with sincerity and commitment. That is all that is needed in the first place, a step which has already proved to be the prime key to success in the West, the Soviet Union, China and Japan.

Many important plans in India have already failed because neither the planners nor the executors did their jobs properly. People are willing, for as long as a year if necessary, to weigh all the pros and cons before for example buying a motor car for themselves, but will lay out a hundred times as much on an expensive official project after as little as two weeks consideration. If that project is doomed to fail, it is not because of any failure of hands or brain, but because of a lack of commitment. The chance of success depends much more on this factor than merely saying later that the project had been too ambitious. One must go for ambitious projects, but wholeheartedly.

Another problem for India is that it is producing more specialists than it needs. In the United Kingdom, only 2.5 per cent of students go to university, but in India, the fraction is about 15 per cent. This means not only that some incompetent students sneak into higher education, but also promotes a brain drain to other countries or to other types of lucrative jobs. The aim of the universities is quite lost in the burden of teaching, while the research institutions fail to hold the meritorious scholars, because of either poor rewards or poor guidance. The latter seems to be the greater problem. Unless the professor or director is prepared to do more brain work than his subordinates, there is no justification for either his rank or the wastage of national money on him. Only a very committed leader can create an atmosphere conducive to equal commitment from his staff. Will the right people ever set the right examples? Department of Physics, N.C. RANA Science Laboratories,

University of Durham,

Durham DHI 3LE, UK

(On leave from Tata Institute of Fundamental Research, Bombay 400 005, India.)

\section{Suggested remedies}

SIR - For the sake of completeness of your appraisal of Indian universities (Nature $308,581-600 ; 1984)$, I would like to add the following comments on higher education in India.

Since independence in 1947, India has taken big strides in higher education, especially in science and technology. In the past two decades, the number of institutes of higher learning has increased enormously, but the provision of new institutes without consolidating the existing ones has had an undesirable effect on the quality of education. Indeed, many institutes have become degree-granting bodies rather than places of learning.

Almost all universities suffer from the age-old problem of "inbreeding". Unlike those elsewhere, Indian students after graduation are usually employed at their own alma mater, and even a very bright graduate will have a tough time getting a job at any other university. As a result, some universities have certain departments specializing in only one discipline - that of the preceptor. This has essentially stifled the influx of new ideas and progress and also creates a situation in which the head of a department, being senior to the rest of the faculty, has an absolute say in the running of his department. His colleagues, most of whom were his own students, do not dare to voice their feelings. Since the fate of an individual faculty member is decided by only one person, the spirit of competition is lost at the very beginning of tenure and every faculty member has to promote himself by means other than teaching and research. With the increasing linguistic chauvinism in the universities, science education has suffered a great deal. A developing country such as India needs ideas and literature from the advanced countries. But since education in English has been trimmed to promote one of the fourteen official languages of India, students cannot grasp the progress of developed nations. This is a self-defeating and shortsighted approach which has been forced on the country by self-promoting educationists and politicians. The effect has inevitably been an overall decline of science and technology education in India.

Striking has become a pastime for Indian students. Students go on strike for a difficult question paper, for failing grades or for compulsory promotion, but never for better teachers. Since the strikes are almost invariably resolved to the students' advantage, they have become an important tool in obtaining degrees, mainly because many students are admitted to university who are not sufficiently well qualified to be there.

India must find ways to eliminate the pitfalls inherent in the existing system. To start with, there should be a ban on appointments to a faculty from among its own graduates. English should be made essential for prospective scientists and technologists. There should be a nationwide qualifying test for university entrance. Educationalists and politicians should do everything they can to formulate progressive and farsighted policies on education and should rise above petty political advantage. It is after all education which eventually leads a nation.

3420 Wythe Road, KAILASH C. GUPTA Memphis, Tennessee 38134, USA

\section{Red Sirius}

SIR - The correspondence about Homer's wine-coloured sea reminds me about red Sirius. Several ancient authors call Sirius red, even though it is white with a slight bluish tint. This is another object which seems to have been called red even though blue would have been a better description.

GÖRAN H. I. JOHANSSON

Lund Observatory,

Box 1107,

S-22104 Lund, Sweden

SIR - Homer's wine-dark sea is not the only such problem in Greek culture. It is wellknown by astronomers that in Ptolemy's Almagest, Sirius is described as a red star, and there is no explanation on modern astrophysical grounds for such obvious disagreement.

Carlos Alberto P.C.O. TORRES Observatório Astrofisico Brasileiro,

Caixa Postal 21,

37.500 Itajuba MG, Brazil 